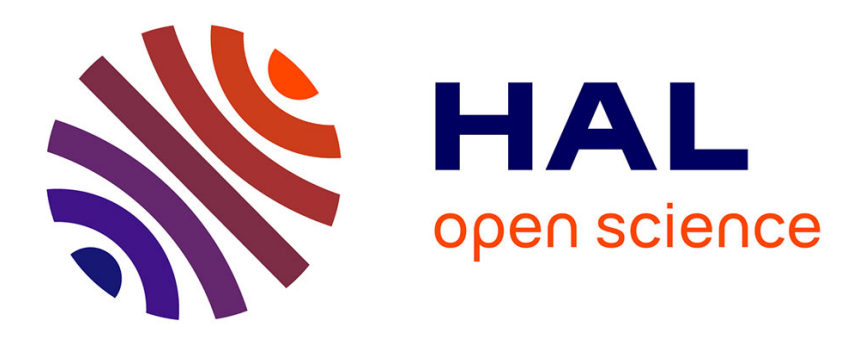

\title{
Liénard systems and potential-Hamiltonian decomposition III - Applications
}

Nicolas Glade, Loïc Forest, Jacques Demongeot

\section{To cite this version:}

Nicolas Glade, Loïc Forest, Jacques Demongeot. Liénard systems and potential-Hamiltonian decomposition III - Applications. Comptes rendus de l'Académie des sciences. Série I, Mathématique, 2007, 344, pp 253-258. hal-00211818

\section{HAL Id: hal-00211818 https://hal.science/hal-00211818}

Submitted on 23 Jan 2008

HAL is a multi-disciplinary open access archive for the deposit and dissemination of scientific research documents, whether they are published or not. The documents may come from teaching and research institutions in France or abroad, or from public or private research centers.
L'archive ouverte pluridisciplinaire HAL, est destinée au dépôt et à la diffusion de documents scientifiques de niveau recherche, publiés ou non, émanant des établissements d'enseignement et de recherche français ou étrangers, des laboratoires publics ou privés. 


\title{
Systèmes de Liénard et décomposition potentielle-Hamiltonienne - III Applications
}

\section{Liénard systems and potential-Hamiltonian decomposition - III Applications}

\author{
Nicolas GLADE ${ }^{\mathrm{a}}$ Loic FOREST ${ }^{\mathrm{a}}$ Jacques DEMONGEOT $^{\mathrm{a}, \mathrm{d}}$ \\ a TIMC-IMAG UMR CNRS 5525 \\ University J. Fourier Grenoble \\ Faculty of Medicine 38700 La Tronche France \\ ${ }^{\mathrm{d}}$ Institut Universitaire de France \\ Tel. 0456520108 \\ FAX 0476768844
}

\begin{abstract}
In the two previous Notes, we described the mathematical aspects of the potential-Hamiltonian (PH) decomposition, in particular for n-switches and Liénard systems [1]. In the present Note, we give some examples of biological regulatory systems susceptible to be decomposed. We show that they can be modeled in terms of 2D-ODE belonging to n-switches and Liénard system families [2]. Although simplified, these models can be decomposed in a set of equations combining a potential and a Hamiltonian part. We discuss about the advantage of such a PH-decomposition for understanding the mechanisms involved in their regulatory abilities. We suggest a generalized algorithm to deal with differential systems having a second part of rational fraction type (frequently used in metabolic systems). Finally, we comment what can be interpreted as a precise signification in biological systems from the dynamical behaviours of both the potential and Hamiltonian parts.
\end{abstract}

\section{Résumé}

Dans les deux Notes précédentes [1], nous avons décrit la décomposition potentielle-Hamiltonienne pour des systèmes de type n-switch ou Liénard. Leurs équations sont bien adaptées à la modélisation des systèmes dynamiques en biologie. Nous donnons ici des exemples de systèmes de régulation biologique pouvant être écrits sous la forme d'équations de Liénard et également sous forme de systèmes n-switch $[1,2]$. Nous discutons ensuite de l'intérêt de connaître les contributions potentielles et Hamiltoniennes de ces systèmes dans la compréhension de leurs mécanismes. Pour terminer, nous suggérons un algorithme prenant en compte des systèmes différentiels à second membre de type fraction rationnelle rencontrés dans les modèles métaboliques, pour lesquels les parties potentielle et Hamiltonienne ont des significations biologiques précises. On explique comment utiliser en pratique cette décomposition au voisinage de leurs attracteurs.

\section{Version Abrégée}

Les systèmes de Liénard et les systèmes de type n-switch sont fréquemment utilisés pour modéliser des systèmes biologiques régulés, au niveau physiologique (système mono-organe comme le système cardiaque, respiratoire ou neural, et systèmes pluri-organes, comme le système végétatif, par couplage de systèmes de

\footnotetext{
Email addresses: nicolas.glade@imag.fr (Nicolas GLADE), loic.forest@imag.fr (Loic FOREST), jacques.demongeot@imag.fr (Jacques DEMONGEOT).
} 
Liénard) ou au niveau moléculaire (processus morphogénétiques, où la composante n-switch représente la partie réactionnelle d'un système de diffusion-réaction). La décomposition potentielle-hamiltonienne [1] proposée pour traiter de tels systèmes permet de séparer leurs paramètres responsables de la bifurcation en régime oscillant en trois familles : l'une qui contrôle la période des oscillations (paramètres apparaissant dans la partie hamiltonienne), l'autre qui contrôle leur amplitude (paramètres apparaissant dans la partie potentielle), et la dernière qui contrôle à la fois la période et l'amplitude (paramètres apparaissant dans les deux parties de la décomposition potentielle-hamiltonienne). La signalisation des systèmes régulés fait en effet fréquemment appel à des modulations distinctes (de fréquence et d'amplitude) et il est essentiel de distinguer les paramètres relevant de chacune de ces modulations du signal.

Un premier exemple d'application est constitué par les équations de Liénard, qui sont des Equations Différentielles Ordinaires de Dimension 2 (2D-EDO) du type : $d x / d t=y, d y / d t=-g(x)+y f(x)$, où $f$ et $g$ sont des polynômes. Par exemple, dans le système de van der Pol [3], nous avons : $g(x)=x$ et $f(x)=\mu\left(1-x^{2}\right)$ et le système de FitzHugh-Nagumo [7-9] n'est qu'une variante de ce système de van der Pol, obtenue par un changement de variable (cf. Figure 1). Les deux systèmes ont en particulier le même réseau isochrone (cf. Figure 2).

L’intégration cardio-respiratoire, dans le système régulé végétatif, peut se modéliser par un couplage d'équations de van der Pol (cf. Figure 4) :

$d x / d t=y, d y / d t=-x+\varepsilon y\left(1-x^{2}\right)$,

$d z / d t=w, d w / d t=-z+\eta\left(1-z^{2}\right) w+k(y) y$

où $k(y)$ représente le coefficient de couplage. Le calcul de la période d'entraînement du deuxième système de van der Pol par le premier, à travers ce couplage, donne la valeur : $T=2 \pi / \sqrt{\left(1-\left(\eta\left(1-(h(y) y)^{2}\right)\right)^{2} / 4\right)}$

L'expression de $T$ traduit l'influence du rythme respiratoire sur le rythme cardiaque (phénomène appelé arythmie respiratoire sinusale), dont la surveillance des variations est cruciale, pour vérifier l'intégrité du système végétatif de régulation cardio-respiratoire.

Si le couplage d'équations de Liénard met en jeu plus de deux systèmes, on peut être amené, à la limite, à étudier une Equation aux Dérivées Partielles (EDP) de type Burger, pour mettre par exemple en évidence des ondes progressives.

Si l'on considère enfin des systèmes métaboliques périodiques, régis par des cinétiques classiques de type michaëlien ou de type allostérique, on peut également obtenir une décomposition potentielle-hamiltonienne au voisinage de leurs cycles-limites, si ceux-ci sont proches de la bifurcation qui leur a donné naissance.

\section{Introduction}

Liénard and n-switches systems have served as paradigm or toy models for many biological regulatory systems (cardiac, respiratory, neural,...) and morphogenetic processes (e.g. in embryogenesis and neogenesis) presenting a periodic temporal behavior with relaxation waves for excitable cells isolated or connected in functional tissues and spatio-temporal patterns if they belong to regulatory and/or morphogenetic networks. In tissues, these interacting cells can cause solitary waves or periodic spatial structures stationary in time (participating to the determination of the anatomy of the tissue by generating the morphology of the corresponding organ). They can also produce periodic structures in time, acting as intercellular or tissular signal triggers, e.g. provoking a collective behavior, the best example being the cardiac tissue in the heart. These systems are frequently used and we give here some examples of their use.

\section{Liénard systems as a paradigmatic model for biological regulatory systems}

\subsection{Classical examples of Liénard systems in biological modelling}

Liénard equations are 2D-ODEs defined by: $d x / d t=y, d y / d t=-g(x)+y f(x)$, where $g$ and $f$ are polynomials. They have been used in physiology to simulate both the heart and respiratory system (van der Pol equations original [3] and modified [4]) and the nerve impulse (FitzHugh-Nagumo equations [5,6]). FitzHugh-Nagumo equations are just a 2D approximation of the Hodgkin-Huxley equations, fundamental in neurobiology [7-9]. 


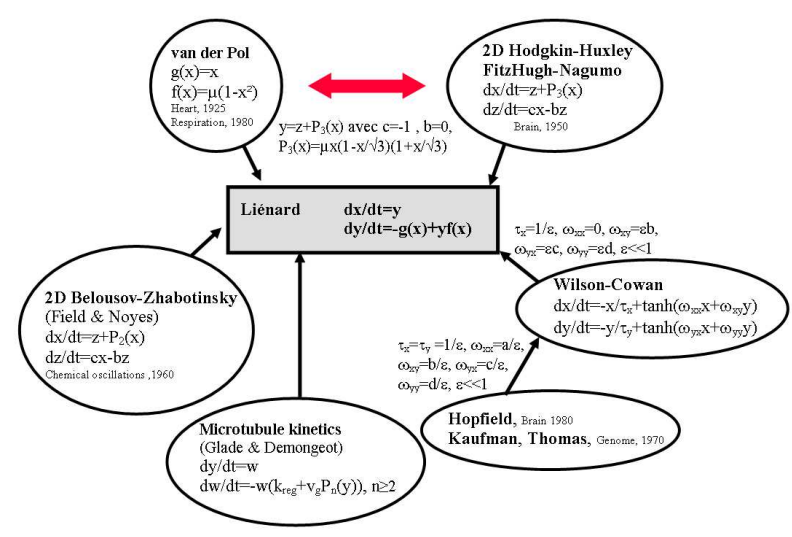

Figure 1. - An overview of Liénard systems in biological models.

FitzHugh-Nagumo equations can be approached by the Wilson-Cowan system [10,11]. It has, in certain parametric circumstances, the same behavior than the Hopfield equations. In addition, the kinetics of the in vitro self-assembly of populations of microtubules, major elements of the cell skeleton, can be approached by Liénard systems by considering assembled (microtubules) and non-assembled (free tubulin molecules) species. Finally, Liénard systems are used for modelling oscillatory chemical reactions, for example the Belousov-Zhabotinsky reaction (Noyes equations $[12,13]$ ). These examples illustrate the universality of the Liénard systems (Fig. 1), which definitively constitute the natural mathematical framework in which many biological and chemical equations can be imbedded.
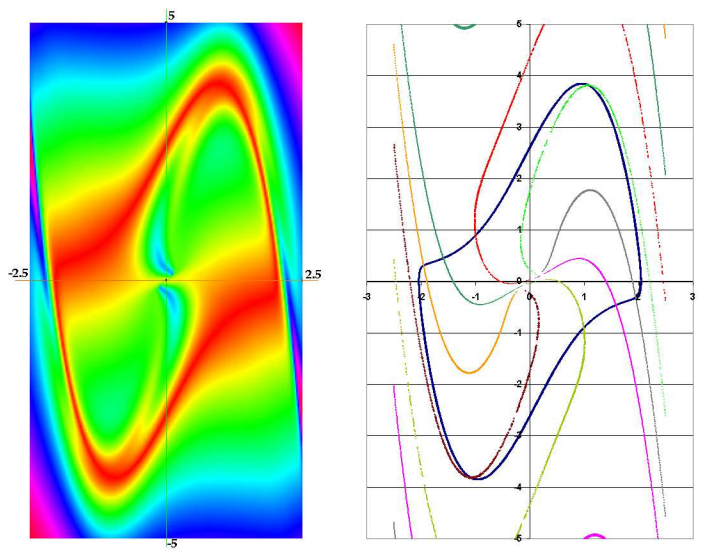

Figure 2. - False color representation of the velocity vectors norm for a van der Pol system (left) and isochronal fibration (right) (for $\mu=2$, limit cycle period $T \simeq 7.642$ ).

As presented in the previous note [1], one of their main properties is their ability to modelize periodic behaviors with simple isochronal patterns (Fig. 2) susceptible to explain the entrainment of biological systems by instantaneous or periodic stimulations.

\subsection{The example of the regulon}

The regulon structure is frequently observed in biology. It is made of a loop of activation and inhibition between two components $\mathrm{A}$ and $\mathrm{B}$, with a self-activation of $\mathrm{A}$. One can observe it for example in the CRO operon of the phages $\lambda$ and $\mu$, or in excitable networks such as the hippocampus, the bulbar respiratory center, the heart (phenomenon called the respiratory sinus arrhythmia),... (Fig. 3). The regulon can have two stable steady states (due to the presence of the positive loop for the multi-attractority and of the negative one for the stability $[14,15])$. One can note that a Liénard system is a regulon, where A (resp. B) is represented by the variable $y$ (resp. $x$ ), if $g, f>0$ and $-g^{\prime}+y f^{\prime}<0$. 


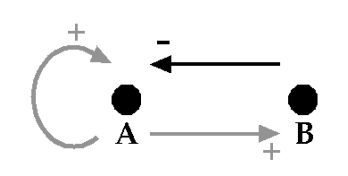

Figure 3. - Regulon scheme. Grey arrows are activatory $(+)$ whereas the black one is inhibitory (-). A activates the formation of $\mathrm{B}$ and its own formation (self-catalysis), whereas B inhibits the formation of A.

\subsection{Examples in cardiac and respiratory coupled systems}

To represent the vegetative control system of the cardiac and respiratory functions, let's consider two regulon-type coupled oscillators in interaction [16,17]. Indeed to simplify, we consider I, a set of inspiratory neurons (a center firing synchronously with the phrenic nerve) having a self-activatory loop and interacting with E, a set of expiratory neurons (a center firing during the phrenic silence) ; E is activated by I (via the pleural stretch receptors) and E inhibits I (through intra-bulbar connections) (Fig. 4).

We neglect in this simplified description other classical groups of neurons corresponding to the Richter classification. Taking them into account leads to a system of higher dimension having the same qualitative dynamical properties, in particular the entrainment ability [4]. In the same way, by neglecting the peripheral Aschow-Tawara node, we consider the cardiac control system as made of 2 groups of excitable cells, one located in the bulb, composed of neurons and called the cardio-modulator center CM, and the other located in the heart septum, called the sinusal node S (Fig. 4).

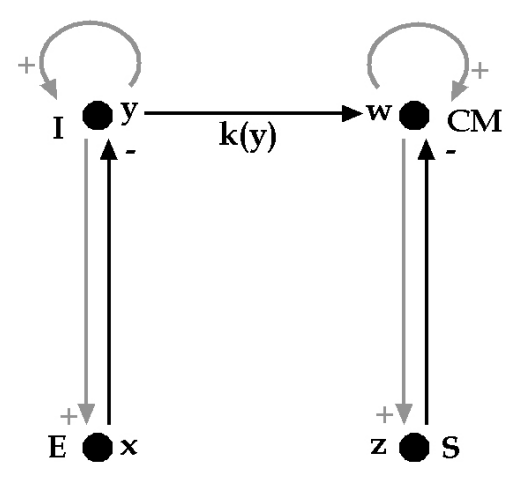

Figure 4. - Coupling between the respiratory oscillator (left) and the cardiac oscillator (right).

The van der Pol system representing the rythmic respiratory activity is $d x / d t=y, d y / d t=-x+\varepsilon y\left(1-x^{2}\right)$, where $\varepsilon$ represents the anharmonic parameter. This oscillator has a free run (proper period) $\tau$ equal (near the bifurcation of the van der Pol limit cycle obtained for $\varepsilon=0$ ), to the ratio $\tau=2 \pi / \operatorname{Im}$, where $\operatorname{Im}=\sqrt{1-\varepsilon^{2} / 4}$ is the imaginary part of the eigenvalues of the Jacobian matrix $J$ of the van der Pol system:

$J=\left[\begin{array}{cc}0 & 1 \\ -1-2 \varepsilon x y & \varepsilon\left(1-x^{2}\right)\end{array}\right] \quad$ taken at the stationary point $(x=0, y=0)$

The van der Pol system representing the rythmic cardiac activity is $d z / d t=w, d w / d t=-z+\eta(1-$ $\left.z^{2}\right) w+k(y) y$, where $\eta$ is the anharmonic parameter and $k(y)$ is the coupling intensity between I and CM. The entrained period of the cardiac oscillator is approximately equal (if $\eta$ is small) to:

$T=2 \pi / \sqrt{1-\left(\eta\left(1-(k(y) y)^{2}\right)\right)^{2} / 4}$

Values of $\varepsilon$ et $\eta$ are fixed by the proper periods of the respiratory (4 seconds) and cardiac ( 1 second) oscillators. $k(y)$ is obtained by measuring the instantaneous cardiac period T (inter-beats duration) and calculating the slope of the regression line between $\mathrm{T}$ and the inspiratory activity $y^{2}$ (represented by the local inspiratory time counted from the beginning of an inspiration, when the cardiac beat of period $\mathrm{T}$ is occurring). This slope is approximated by $-\pi(\eta k(y))^{2} / 2$, if $\eta$ and $k(y)$ are small, and is estimated by the correlation coefficient $\varrho$ between $\mathrm{T}$ and $y^{2}[16,17]$ multiplied by the ratio between standard deviations of $\mathrm{T}$ and $y^{2}$.

The integrity of the coupling between the 2 Liénard systems [18] allows the bulbar vegetative control system to adapt to the effort: first the breathing is entrained by a muscular activity and secondarily entrains 
the heart (phenomenon called the Respiratory Sinus Arrhythmia, RSA). Such a capacity of adaptation disappears in degenerative diseases like Parkinson or diabetes. Watching a parameter like $\varrho$ is then interesting in elderly people surveillance and the at home watching systems will conversely permit the emergence of a new knowledge about the vegetative regulation and the improvement of the at home rehabilitation systems.

More generally, the study of series of coupled oscillators is necessary to explain synchronization, desynchronization and entrainment phenomena [10]. According to the previous example, we can establish the series of oscillators : $i=1, . ., N, d x_{i} / d t=y_{i}, d y_{i} / d t=-g\left(x_{i}\right)+g\left(x_{i-1}\right)+y_{i} f\left(x_{i}\right)$

The continuous limit in $i$ leads to the partial differential equation (PDE):

$\partial^{2} x / \partial t^{2}=f(x) \partial x / \partial t-g^{\prime}(x) \partial x / \partial s$

This new class of PDE is an extension of Burger's equation (by exchanging the role of $s$ and $t$ [19]) and has to be studied in future articles (existence and unicity of solutions, travelling waves, conservative properties,... ).

\subsection{Extension to metabolic systems}

In genetic or metabolic regulatory systems, we can sometimes extract a potential and a Hamiltonian part $[1,20]$. If we suppose that enzyme kinetics are of Michaëlian or allosteric type, a polynomial $P\left(x_{i}\right)$ exists of order $n$ (called 'cooperativity'), where $x_{i}$ is the concentration of the substrate catalysed by the $i^{\text {th }}$ enzyme of the metabolic system, then the degradation rate of $x_{i}$ is given - if no other metabolite contributes to its catabolism - by $\left(-\partial \log P\left(x_{i}\right) / \partial \log x_{i}\right) / n$. In general, the corresponding differential system has a principal potential part (the system tends to become a gradient system when $\left\|x_{i}\right\|$ tends to infinity [20]), in particular because of the saturation of terms like $\left(\partial \log P\left(x_{i}\right) / \partial \log x_{i}\right) / n$. Then we can prove easily by denoting $y_{i}=\log x_{i}$ (the de Donder chemical affinity [21,22]) that if there are 2 enzymes in the metabolic system with the same cooperativity $n$ and if the substrate $x$ enters with a constant flux $\sigma$, we have:

$d y_{1} / d t=\exp \left(-y_{1}\right)\left(\sigma-\partial \log P_{1} / \partial y_{1}\right) / n, \quad d y_{2} / d t=\exp \left(-y_{2}\right)\left(\partial \log P_{1} / \partial y_{1}-\partial \log P_{2} / \partial y_{2}\right) / n$

This system is $\mathrm{PH}$-decomposable into two analytic parts in the neighbourhood of a fixed point or of a just bifurcating limit cycle for which $\exp \left(-y_{i}\right)$ 's can be considered as constant, with the potential $P=$ $\left(\log P_{1}\left(y_{1}\right)+\log P_{2}\left(y_{2}\right)\right) / n$ and the Hamiltonian $H=\sigma y_{2}-\left(\log P_{1}\left(y_{1}\right)\right) / n$.

An advantage of this decomposition is the parting of the set of parameters into 3 distinct families: amplitude controlling parameters (appearing in $\mathrm{P}$ only, like $P_{2}$ parameters), period controlling parameters (appearing in $H$ only, like $\sigma$, which is also involved in the values of the stationary states) and mixed parameters (appearing both in $P$ and $H$, like $P_{1}$ parameters). Although the $\mathrm{PH}$-decomposition is not unique, this parting of the parameters can be crucial to understand the origin and the control of the cell signalling or tissue morphogenesis.

\section{Conclusion}

In the two previous Notes [1] we developed a new method for algebraically approximating limit cycles of classical dynamical systems like n-switches, Lotka-Volterra and Liénard systems, allowing to separate the flow into two parts, a dissipative one called potential (or gradient) and a conservative one called Hamiltonian, whose parameters have different roles, with more amplitude modulating in the dissipative part and more frequency modulating in the conservative one. The specific power of each parameter will be evaluated in the future from generalization of the control strenghts, currently avalaible only in case of stationary states or of relaxation oscillations [23-25]. It will allow to a practical use of the present approach in all biological applications described in this paper and in others of the same type in narrow fields (population dynamics, genetic control, immunologic response,... ).

\section{Acknowledgements}

We are very indebted to A. Winfree (died in November 2002) for having introduced the notion of isochron and for having given one of the first convincing examples of application of dynamical systems theory in biology, and to J.P. Françoise for stimulating discussions and helpful suggestions. 


\section{References}

[1] Demongeot J., Glade N., Forest L., Liénard systems and potential-Hamiltonian decomposition - I Methodology and II Algorithm, C. R. Acad. Sci., Mathématiques (in press)

[2] Cinquin O., Demongeot J., High-dimensional switches and the modeling of cellular dfferentiation, J. Theor. Biol. 233 (2005) 391-411.

[3] van der Pol B., van der Mark J., The heartbeat considered as a relaxation oscillation and an electrical model of the heart, Philos. Mag 6 (1928) 763-775.

[4] Pham Dinh T., Demongeot J., Baconnier P., Benchetrit G., Simulation of a biological oscillator: the respiratory rhythm, J. Theor. Biol. 103 (1983) 113-132.

[5] Nagumo J., Arimoto S., Yoshizawa S., An active pulse transmission line simulating nerve axons, Proc. IRL 50 (1960) 2061-2070.

[6] Fitzhugh R., Impulses and physiological states in theoretical models of nerve membranes, Biophys. J. 1 (1961) $445--466$.

[7] Hodgkin A.L., Huxley A.F., A quantitative description of membrane current and its application to conduction and excitation in nerve. J. Physiol. 117 (1952) 500-544.

[8] Thom R., Topological models in biology, Topology 8 (1969) 313-335.

[9] Zeeman C., Differential Equations for the Heartbeat and Nerve Impulse, in: Dynamical Systems Symposium Univ. Bahia, Academic Press, New York, 1973, pp. 683-741.

[10] Tonnelier A., Meignen S., Bosch H., Demongeot J., Synchronization and desynchronozation of neural oscillators: comparison of two models, Neural Networks 12 (1999) 1213-1228.

[11] Demongeot J., Kaufmann M., Thomas R., Positive feedback circuits and memory, C.R. Acad. Sc., Sciences de la Vie 323 (2000) 69-79.

[12] Glansdorff P., Prigogine I., Thermodynamic theory of structure, stability and fluctuations, Wiley, New York (1971).

[13] Tyson J.J., The Belousov-Zhabotinskii reaction, Lect. Notes in Biomaths 10 (1976).

[14] Cinquin O., Demongeot J., Positive and negative feedback: striking a balance between necessary antagonists, J. Theor. Biol. 216 (2002) 229-241.

[15] Cinquin O., Demongeot J., Positive and negative feedback: mending the ways of sloppy systems, C. R. Acad. Sci. Biologies 325 (2002) 1085-1095.

[16] Demongeot J., Virone G., Duchêne F., Benchetrit G., Hervé T., Noury N., Rialle V., Multi-sensors acquisition, data fusion, knowledge mining and alarm triggering in health smart homes for elderly people, C. R. Acad. Sci. Biologies 325 (2002) 673-682.

[17] Ben Lamine S, Calabrese P, Perrault H, Dinh TP, Eberhard A, Benchetrit G., Individual differences in respiratory sinus arrhythmia, Am J Physiol Heart Circ Physiol. 286 (2004) 2305-2312.

[18] Murray J.D., Mathematical Biology, Springer, Berlin (1989).

[19] Thibault S., Heyer L., Benchetrit G., Baconnier P., Ventilatory support: a dynamical systems approach, Acta Biotheoretica 50 (2002) 269-279.

[20] Demongeot J., Existence de solutions périodiques pour une classe de systèmes différentiels gouvernant la cinétique de chaînes enzymatiques oscillantes, Lect. Notes in Biomaths 41 (1981) 40-62.

[21] de Donder T., Thermodynamic Theory of Affinity: A Book of Principles, Oxford Univ. Press, Oxford, 1936.

[22] de Donder T., Sur la théorie des invariants intégraux, Ph.D. thesis ULB, Brussels, 1899.

[23] Baconnier P., Pachot P., Demongeot J., An attempt to generalize the control coefficient concept, J. Biol. Systems 1 (1993) 335-347.

[24] Demongeot J., Esteve F., Pachot P., Comportement asymptotique des systèmes : applications en biologie, Rev. Int. Syst. 2 (1988) 417-442.

[25] Ruoff P., Christensen M.K., Wolf J., Heinrich R., Temperature dependency and temperature compensation in a model of yeast glycolytic oscillations, Biophysical Chemistry 106 (2003) 179-192. 